\title{
A Garbage Crisis
}

\section{Must We Solve Anew the Problem of the Disposition of Domestic Wastes?}

\author{
By Harry A. Mount
}

H, for a Moses of the Garbage Can! For forty years engineers in this country have been leading certain industries and our municipalities toward a Promised Land, where garbage and similar materials would cease to be merely wastes that must be disposed of at large expense, but would be made to yield valuable products which would pay for their disposal, or might even show a balance on the profit side of the ledger.

Now it appears that what we thought was the Promised Land just ahead was perhaps only a mirage, for an economic condition has arisen which apparently makes the plan impossible of success and all of the progress of nearly a half a century along this line may be wiped out. Where is the man, or where is the idea, that can save the $\$ 7,500,000$ invested in garbage reduc tion plants still operating, which embody the best thought American engineers could offer to those confronted with problem of garbage disposal?

In brief, the present-day system of garbage reduction (the only system which seeks to turn to economical use the constituents of garbage) is founded on the thought that some of the contents of garbage are valuable. Destroy this value and the whole system falls. That is what has happened.

Garbage ought to be regarded as a liability and not an asset. The problem primarily is to be rid of the garbage as cheaply as possible in an inoffensive manner. Normally the reduction process meets these requirements perfectly, and, as well, salvages the useful material present.

The principal material salvageable from garbage is grease. For the ten years prior to the war this grease found a ready market among soap and candle makers. The value of garbage grease reached a peak during the War and it seemed as if the success of the scheme was certain. But since the signing of the armistice this country has been flooded with millions of pounds of oils from the Orient, and tallow from South America, produced in these countries so cheaply that competition with them is impossible. These products have the additional advantage that they are cleaner than garbage grease and therefore do not have to be so thoroughly processed by the soap or candle maker. The South American tallow supplies candle makers with a first-rate product at a minimum of cost and the soap maker has his choice of such Oriental products as soy bean oil, non-edible fish oils, and wool grease. These come chiefly from China, Japan, Korea, Manchuria, and India.

In the ten years from 1905 to 1914 , in clusive, garbage reduction plants had no difficulty in disposing of their garbage grease at an average price of $4 \frac{1}{4} \mathrm{c}$ a pound. During the war, two or three times that much could be had and the demand greatly exceeded the supply. Now the best price obtainable is from $11 / 4 \mathrm{c}$ to $2 \mathrm{c}$ a pound (dependent on quality and distance it must be hauled), and there is little or no market at any price. This fact, coupled with other unfavorable circumstances, has made it impossible to operate a garbage reduction plant excep at a large loss. This means that all of the privately owned plants which have not already shut down will soon have to do so, and sooner or later the municipal plants must follow their example.

The tragedy is not so much in the money loss involved as in the fact that the state of the art will be set back a good forty years. There is no other method of garbage disposal which has been widely accepted as satisfactory.

It is true that there are methods of garbage disposa now in use which are much more widely used than reduction, but these are admittedly makeshift methods or of doubtful economic value.

It is true, also, that there is a great diversity of opinion as to whether reduction is the best method of garbage disposal. But the idea has been steadily gaining ground in the past few years and with improvement in machinery and methods it has shown steadily bette results. The system as it is usually carried out consists in "digesting" the garbage by steam cooking un der pressure in large tanks. This breaks down the materials so that the grease can be extracted. The solids which remain are partially dehydrated and sold as "tankage" for use as fertilizer.

in addition to the grease, 60,000 tons of fertilizer, sufficient to grow a 3,000,000 bushel wheat crop."

W. J. Springborn, a noted authority on garbage disWosal, estimates that under normally favorable conditions, the reduction system might be expanded to economically care for the garbage from all American cities of more than 100,000 population. From these there could be recovered yearly about $135,000,000$ pounds of grease and 265,300 tons of fertilizer, the combined value of which would be nearly $\$ 11,000,000$. The railroads would receive nearly $\$ 2,000,000$ for hauling the grease and fertilizer and another $\$ 725,000$ for freight on coal and other supplies needed by the plants.

As a matter of fact, during the war even better results than these were obtained from our army cantonments. The situation was most favorable, here, however, because the separation, collection, etc., of the garbage could be most closely controlled. In spite of the fact that wherever a good dumping place could be found (as a large body of water) no attempt was mạde at reduction, the sale of the camp wastes developed a revenue of more than $\$ 1,000,000$ a year.

At this writing twenty-four large garbage reduction plants are still in operation in this country, many others having shut down. Of these plants, fourteen are owned by municipalities, as follows: Chicago, Philadelphia, Cleveland, Indianapolis, Washington, Rochester, Columbus, Syracuse, Dayton, Bridgeport, New Bedford, Wilmington, Del., Reading, and Schenectady. The remaining ten are operated as private enterprises and dis-

Top view of garbage digesters

The optimism with which the process was generally regarded may be surmised from the following paragraph from a bulletin issued in 1919 by the Department of Agriculture :

"Several important sources of recoverable fats and oils are still overlooked in this country. One of the promising of these is city garbage. Some idea of the total amount of grease that might be recovered from our domestic wastes may be gained from the actual yield of $4,000,000$ pounds from the reduction plant operated by the city of Chicago. Armour \& Company

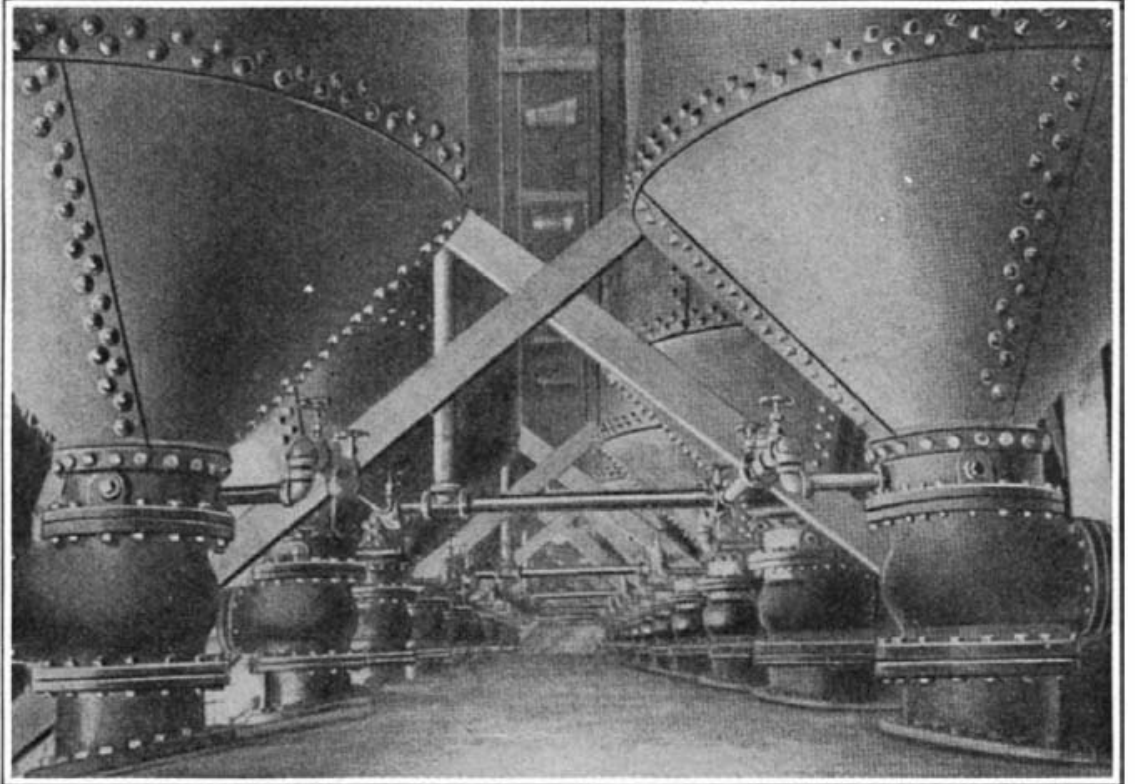

The digesters as they appear from below contracted to buy this quantity of grease from the city at a price of 11.57 cents a pound in 1918 and the Fmery Candle Co. pays 13.5 cents a pound for a simllar grease obtained from Washington garbage. It has been stated by an authority on the subject of garbage disposal that $30,000,000$ pounds, over $\$ 3,000,000$ worth of grease, which could be converted into $4,400,000$ pounds of nitroglycerine and almost 40,000 twelve-ounce cakes of soap, goes to waste in 24 hours in our large cities alone. If this garbage from a combined population of 5,000,000 were properly utilized, we would get,

\section{each on a contract basis.}

In allition to these, numerous plants have closed down all over the country. A great plant on Staten Island, constructed by private enterprise at a cost of more than $\$ 3,000,000$, to dispose of the garbage from New York City, has recently been sold as junk for $\$ 225,000$. The immediate prospect is most uninviting What is to be done? Cities must continue to dispose of their garbage in as nearly as possible an inoffensive manner regardless of the merits of the several systems of disposal or the economic situation.

It would seem at first thought that great hog farms might solve the garbage problem for large cities. It is pretty generally a practise among smaller American cities to feed the garbage to hogs. Rudolph Herring, a New York engineer, who has been the most prolific writer on the subject of garbage disposal, has this to say of hog feeding in a book just off the press

"The method of disposal by feeding to hogs has spread to many cities. With pork at present prices, garbage will produce from $\$ 7$ to $\$ 8$ in value per ton. Thus for communities where the garbage can be properly collected and controlled, no other method shows equally high returns."

It ought to be noted that the last qualifying sentence almost always limits the usefulness of hog feeding to small cities because it is impossible to control and collect properly the garbage in large cities, or at least because only part of such garbage is useful for hog feeding. Furthermore, it has been pretty definitely proven that garbage is not the best food for hogs under any circumstances and that garbagefed hogs are particularly susceptible, because of lowered vitality, to cholera and other diseases. This introduces into the business of hog feeding a gambling element that increases as the size of the herd and the size of the city furnishing the garbage increases. In spite of these facts several large cities now feed their garbage to hogs, notably Albany, Denver, New Haven, Providence, Springfield, Mass., and Worcester. Many other cities feed to hogs only the choice parts of the garbage, such as is secured from hotels and restaurants, and dispose of the remainder in some other way.

About the only other methods of garbage disposal are 
to dump the waste into some large body of water, throw it on a dump, bury it, and burn it. New York City now utilizes the first of these methods and hauls its garbage to sea and dumps it. But inland cities usually have to choose some other method; and even New York finds the method of dumping at sea not entirely satisfactory, since the barges must go on a long and expensive ocean voyage, or the city's chickens will come home to roost in the form of garbage-strewn beaches. As a matter of fact, on some of the oceanfront near the big city the volume of tidally deposited garbage is right now a serious problem.

In some cases the garbage is plowed under in fields as fertilizer. But the immediate value of garbage as fertilizer is far below what a chemical analysis might indicate because most of the plant food present is not immediately available as such. It must first go through a long process of decay. And then, if the garbage contains much grease, this may clog up the pores of the soil with the effect of stopping the free circulation of air and water, and thus the garbage may even become a detriment to the soil.

Incineration is one of the oldest methods of garbage disposal, and in many respects one of the most promising. This hypothetical new Moses of the Garbage Can might well take a lesson from the Moses of old for it is recorded that during the exodus from Egypt Mose ordered that all offensive and unclean waste be taken outside the camp and burned.

Moses, however, would have wondered at the modern incinerating plants which not only provide a sanitary method of garbage disposal, but by burning the garbage under boilers develop energy in excess of the needs of the plant. The amount of energy available is not great because most of the steam thus generated must be used to dry the garbage before it can be burned. However, steam from such a plant operates a pumping plant for the city of Milwaukee, and the city of Savannah pumps part of its water supply in this manner. There is at least one small installation where this excess steam is turned into electric energy.

The chief difficulty with incineration is that the fumes from the burning garbage are likely to create a public uuisance. The city of New Bedford, Mass, recently had an experience of this sort. New Bedford until recently disposed of its garbage by reduction, but when the plant legan losing large sums of money, an attempt was made to economize by installing a dryer so that garbage could be burned under the digester tank boilers. The fumes inspired such a protest from citizens that the plan was quickly abandoned.

Incinerating furnaces for the purpose of disposing of garbage with no idea of deriving therefrom any useful product or energy have been highly perfected. They consist usually of a coal fire beneath a grate on which the garbage is spread to dry, the dried material finally being fed into the fire and burned.

To the potential Moses of the garbage can, the write has these suggestions as to methods of attacking the problem of economical garbage disposal :

1. Find some new use for garbage grease so that there will be a steady market for this product.

2 Find a method of overcoming the fumes from burning garbage so that the excess calorific value of garbage might be turned into useful energy without creating a nuisance.

3. And, failing in these, find a way to convince a most skeptical world that any method of garbage disposal not yet tried is worth trying.

\section{Aerofoil Data} A visory Committee for Aeronautics, "The Minimum Induced Drag of Aero" foils," by Max M. Munk, helps to explain the phenomenon of flight. It contains some theorems concerning the arrangement of airplane wings which are of considerable practical interest. In particular, it shows the theoretical reasons for the decrease of drag which accompanies all increase in the aspect ratio or lateral extension of a wing. The efficiency of a given arrangement of wings may be calculated from the formulæ in this paper. A copy of this paper, which may be ordered as Report No. 121, may be obtained upon request from the National Advisory Committee for Aeronautics.

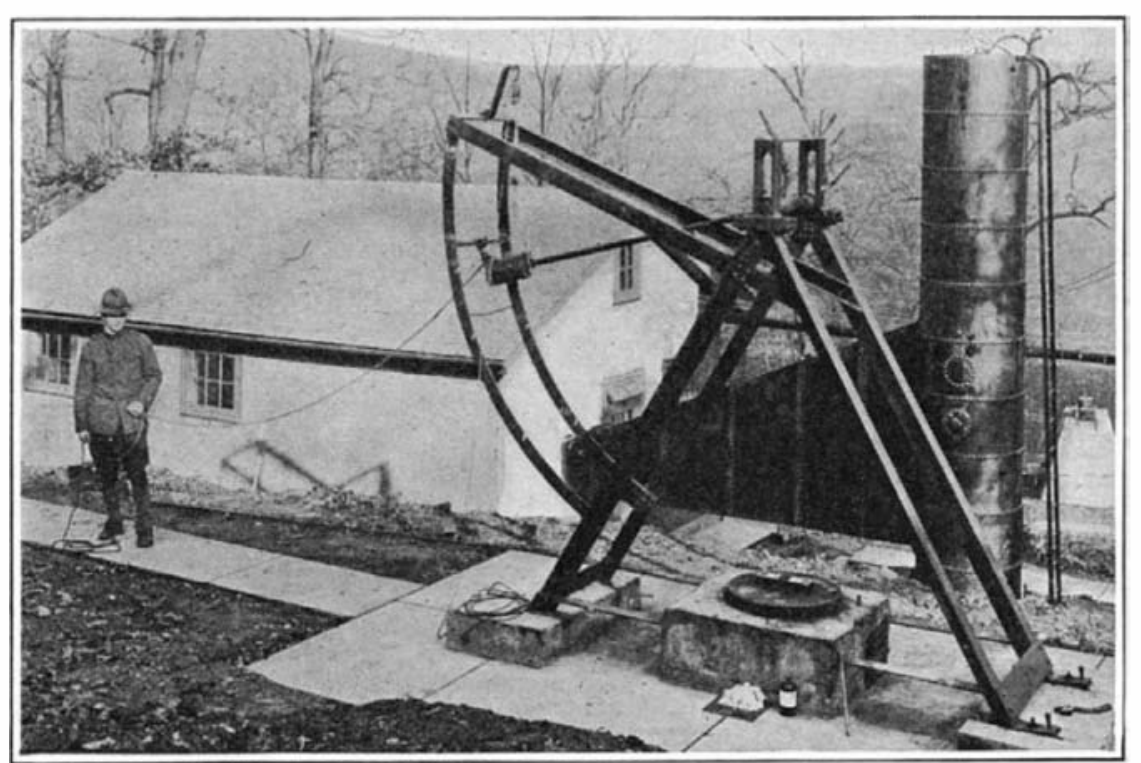

Pendulum friction machine for determining the sensitiveness of explosives

moving upward and is about to start downward-marking this point on the pencil. Approximate top dead center is thus vouchsafed.

The propeller is now turned over in a forward direction until the pencil or scale has moved down so that the mark is even with the top edge of the hole, using the pencil in marking the disk in line with one of the pointers. The engine is given a backward motion until the pencil has moved up and down until the mark is again even with the spark plug hole, the disk being marked in line with the pointer. A pair of dividers will reveal the point between the two pencil marks on the disk. Such point denotes the exact dead center of Nos. 1 and 6 cranks, the propeller being turned until the point just discovered is under the right pointer. Without moving the propeller, the flange is loosened as well as thumbscrews, and the disk is turned by hand until one of the 120-degree marks coincides with the pointer. Screw down the flange and thumbscrews and actual

by means of which it is attached and operated

New Timing Disk Reduces a Day's Work into a Few Minutes

BVIATING the removal and replacement of pro-
pellers, radiator shells and radiators, the laborsaving feature of a new timing disk designed and built by the engineering department of the United States Ai Service at Post Flying Field, Fort Sill, Oklahoma, merits immediate recognition and widespread popularity. Specifically, the instrument was invented for use on Liberty motors, but by slight modifications it is adaptable on airplane engines of any design. The spindle of this disk is provided with tapers and an expansion feature, adjustable to fit into the hub of all Liberty motors

The expansion of the spindle is possible by thumb screws. Freedom to revolve around the spindle is permitted the disk itself until the flange is screwed up, jamming the disk against the back flange, which is staionary on the spindle. Pointers are adjusted 45 degrees apart, indicating the center line of piston travel. Washers and nuts secure the indicator into position. Vertica position for the indicator is insured by a pendulum rod. For the sake of convenience, the indicator is cut int three sections and the ends are threaded so these will screw into another. It can be assembled in the absence of wrenches or tools. The disk is marked every 120 degrees, the notation being the point of top dead center, the crank shaft having three throws of 120 degrees. grees on each side of these 120-degree marks.

Instructions from the Air Service include specific directions for using this timing disk. The tail of the ship is raised, not an absolute requirement, but one giving the pendulum of the instrument full action. The spindle is shoved into the hole of the propeller hub, the adjustable screw being turned until a tight fit is insured. Forthwith the thumbscrew is relieved and the flange is screwed back, thereby permitting the disk to circumven the spindle. The removal of at least one spark plug from each cylinder facilitates turning of the propeller. The top dead center of a cylinder, say, No. 6, is then discovered by inserting a pencil or scale into the sparkplug hole and turning the propeller until the piston, by upward stroke, touches the pencil or scale and causes it to ride up. Continue to turn the engine over slowly until the piston, as directed by pencil or scale, stops when the valves open and close with reference to top and bottom dead center. Once having timed the motor, the disk is subject to removal by loosening the expansion screw and extracting the spindle from the propeller hub. Former designs of timing disks involved a day's labor, whereas the recent invention accomplishes an equal task within a few minutes.

\section{Elevator Interlocks}

IN connection with the safety work of the Bureau of located in several large cities with an idea of analyzin elevator accident statistics as bearing upon the use of safety interlocks. It has been shown that 73.8 per cent of all fatal accidents in connection with elevators which have doors to the shafts could be eliminated by the use of well-designed interlocks. The report has been prepared in the form of Technologic Paper No. 202 of the Bureau of Standards, Washington, D. C.

\section{How Sensitive Is Dynamite?}

INING coal-hazardous occupation that it is-in-
volves the use of explosives in tunneling for the winter's fuel supply. Frequently a cartridge of explosive becomes lodged in a drill hole and in forcing the charge of nitroglycerin or other form of dynamite to the base of the opening, ramming may be resorted to, an exigency that is likely to result in premature combustion unless the frictional resistance of the particular explosive is known. Such advance knowledge may now be ascertained by consulting a machine designed by the United States Bureau of Mines and adapted for use at its explosive experiment station near Bruceton, $\mathrm{Pa}$.

A shoe, a pendulum, and an anvil are the three essen tial parts of the apparatus which lend themselves to easy introduction to the layman in a new guise. The swinging steel shoe, which may be shod with hardwood fiber or a product of more forceful impact, exerts itself in a pendulum-like fashion from varying heights on a steel anvil which contains and exposes the charge of explosive. Smooth-faced, like the anvil of the immortal village blacksmith, to the extent of having a surface $31 /$ inches wide and 12 inches long, in the middle are to be found three grooves for holding the object of the test. The steel shoe has a sway - that is, a radius of swing-of 6 feet $6 \%$ inches and the curvature of its beardless face is $101 \%$ inches. Weights ranging from 2.2 to 44 pounds are employed in varying the force of the blow, the shoe being dropped from heights of 19.7 to 78.7 inches. Some explosives have yielded to the impact of the shoe when shod with wood fiber, while other combustible material is less sensitive even when pounded with harder substances.

Explosives recognized for use in mines, according to the 1920 permissible list of the Bureau of Mines, number 179 as compared with 162 in 1919. Thirty-four new explosives were admitted on the approved schedule, while 17 previously sanctioned were stricken from the list. A digest of the rules, regulations, and practices governing the testing of explosives has been prepared, and all may obtain the report upon application to the Pittsburgh Experiment Station of the Bureau of Mines, Pittsburgh, Pa. 